\title{
O uso da Cartografia Ambiental na Educação Básica como ferramenta de análise dos Impactos Ambientais: estudo de caso do Ribeirão Tabuão de Lorena - SP.
}

\author{
Cleuton Vieira Lima ${ }^{1}$ \\ Maria Dolores Alves Cocco ${ }^{2}$ (Orientadora) \\ ${ }^{1}$ Universidade de Taubaté - Unitau \\ Avenida Carlindo Luiz dos Santos - 12604-420 - Lorena - SP, Brasil \\ cleutonvieira@hotmail.com \\ ${ }^{2}$ Universidade de Taubaté - Unitau \\ Estrada Mun. Dr. José Luiz Cembranelli, 5.000- 12080-010 - Taubaté - SP, Brasil
}

\begin{abstract}
This work has the goal of using the Environmental mapping as a tool for analysis of environmental impacts caused by human activities and who may later be important tools that students of basic education to understand these elements in cartographic representations. For the goal is reached, photographic records were made of the effects and with the help of a high resolution image from Google Earth and the Spring program will be prepared thematic maps for the representation of the environmental problems identified during the Ribeirão Tabuão city of Lorena - SP. With thematic maps completed, use will be a function of that software, it is import symbols for the representations and include them in the maps so that they can be treated almost immediately by your readers, as is characteristic the evocative symbolism.
\end{abstract}

Keywords: environmental mapping, thematic cartography, environmental impacts, basic education, Ribeirão Tabuão

\section{Introdução}

A problemática ambiental cada vez mais ocupa espaço no meio acadêmico e popular. Todas as discussões remontam para ações mitigadoras com relação aos inúmeros problemas ambientais gerados pelas múltiplas atividades antrópicas.

$\mathrm{Na}$ Educação Básica, vários instrumentos são utilizados no processo de ensinoaprendizagem dos alunos, dentre os lúdicos, que otimizam a assimilação dos conteúdos.

A Geografia, que estuda e analisa o espaço através de suas inter-relações, conseqüências e produções, se faz valer da Cartografia, especialmente a Temática para representar o espaço e suas especificidades.

A chamada Cartografia Ambiental, que segundo Martinelli e Pedrotti (2001) é indissociável da Cartografia Temática, representa os diversos impactos no meio ambiente, seja ele local ou global, tem encontrado dificuldades em transmitir o conhecimento aos alunos, sobre as questões ambientais.

O presente estudo, através da percepção desses problemas, procura desenvolver técnicas, métodos de interpretação e leitura cartográfica, que proporcione ao educando uma análise fidedigna dos fenômenos cartográficos e que o mesmo possa relacionar a teoria com a prática em seu espaço de vivência.

$\mathrm{O}$ maior inconveniente apontado pela pesquisa se refere à simbologia utilizada para representar os diversos impactos ambientais nos mapas destinados ao ensino escolar, pois, entende-se, que os alunos têm certa dificuldade de assimilar estas informações por não terem símbolos mais eficazes nas representações cartográficas ou uma linguagem mais acessível. 
A partir deste foco, alguns mapas temáticos serão elaborados com os impactos ambientais identificados na área de estudo e posteriormente pretende-se chegar a uma "fórmula" mais agradável de associação dos ícones cartográficos com seu respectivo impacto.

\section{Objetivos: \\ Geral}

O presente estudo objetiva utilizar as dificuldades de interpretação cartográfica no ambiente escolar, especificamente a Cartografia Ambiental, para propor alternativas de representação com relação à temática ambiental.

Com a identificação dos problemas, pretende-se desenvolver uma metodologia, que proporcione maior facilidade de compreensão dos impactos ambientais recorrentes no cotidiano e no mundo.

\section{Específico}

Através do estudo de caso na cidade de Lorena no Ribeirão Tabuão, objetiva-se identificar os impactos ambientais gerados nas margens do referido ribeirão.

Utilizando a Cartografia Ambiental e um software de geração de representações cartográficas, elaboraremos cartas temáticas demonstrando os impactos ambientais identificados no estudo.

Perceber que utilização da cartografia ambiental, juntamente com recursos visuais de fácil assimilação é importante para facilitar a compreensão dos problemas ambientais que vivenciamos.

\section{Metodologia}

Para a realização deste trabalho, a priori foi definido o Ribeirão Tabuão da cidade de Lorena-SP para estudo de caso, para aplicar a pesquisa referente aos impactos ambientais gerados em suas margens. Um item que contribuiu para o estudo neste Ribeirão foi o fato de seu leito cruzar vários bairros da cidade, principalmente a área central. Posteriormente foram realizadas visitas ao longo do trecho urbano do Ribeirão - onde o acesso foi permitido - para a identificação dos impactos gerados pela ocupação do entorno, além de registro fotográfico (câmera digital de seis megapixels) para a documentação do estudo.

Com a identificação dos impactos, foi gerado uma Matriz de Impactos Ambientais para melhor visualização dos problemas identificados. Para efeito de comparação entre os bairros a respeito da intensidade dos danos ao meio ambiente, os gráficos gerados pelo software Excel ofereceram uma clara percepção das informações apresentadas.

Após as etapas realizadas, um mosaico de imagens gerado com recursos do Google Earth no trecho que percorre o Ribeirão Tabuão, será utilizado para a elaboração de mapas temáticos.

Com a identificação dos impactos, que segundo Silva (2001), são ações desenvolvidas no intuito de implantar e conduzir um empreendimento impactante, os dados serão transferidos para uma linguagem cartográfica e ambiental, por meio do software específico (SPRING) para a geração de dados cartográficos, com uma possível adoção de nova metodologia, que decodifique os símbolos representados nos mapas e facilite a interpretação e transposição dos significados, relacionados à cartografia temática e a co-irmã Cartografia Ambiental, com uma simbologia possivelmente de figuras (evocativas) em oposição à gradação e variação das cores, comumente utilizados.

\section{Resultados e Discussão}

Até o momento podemos observar que ao longo do Ribeirão Tabuão foram identificados impactos diversos, tais como: invasão de APP, lançamento de esgoto in natura, 
ausência de mata ciliar, pastagens, erosão e intensa impermeabilização do solo. Estas informações foram alocadas na Matriz de Impactos Ambientais a seguir.

\begin{tabular}{|l|l|l|l|l|l|l|l|}
\hline \multicolumn{2}{|l|}{ Matriz de Impactos Ambientais do Ribeirão Tabuão gerados pelo uso e ocupação de suas margens } \\
\hline Tipos de impactos & $\begin{array}{l}\text { Invasã } \\
\text { o de } \\
\text { APP }\end{array}$ & $\begin{array}{l}\text { Efluentes } \\
\text { in natura }\end{array}$ & Detritos & $\begin{array}{l}\text { Mata } \\
\text { Ciliar }\end{array}$ & Erosão & Pastagens & $\begin{array}{l}\text { Impermeabiliza } \\
\text { ção do solo }\end{array}$ \\
\hline Jardim Augusta & 2 & 0 & 0 & 2 & 0 & 2 & 1 \\
\hline Parque Mondesir & 0 & 0 & 0 & 2 & 0 & 0 & 2 \\
\hline Vila Santa Maria & 1 & 0 & 0 & 1 & 0 & 0 & 2 \\
\hline Cidade Industrial & 0 & 0 & 0 & 1 & 0 & 0 & 2 \\
\hline Bairro Olaria & 2 & 3 & 3 & 1 & 0 & 0 & 3 \\
\hline Jardim Imperial & 1 & 0 & 1 & 1 & 0 & 0 & 2 \\
\hline $\begin{array}{l}\text { Conj. Hab. Otto } \\
\text { Ude }\end{array}$ & 0 & 0 & 3 & 1 & 0 & 0 & 1 \\
\hline Vila Hepacaré & 0 & 0 & 0 & 1 & 0 & 0 & 3 \\
\hline Vila Buck & 1 & 0 & 1 & 1 & 0 & 0 & 2 \\
\hline Vila Dom Bosco & 1 & 0 & 1 & 1 & 0 & 0 & 2 \\
\hline Matadouro Velho & 1 & 0 & 1 & 1 & 3 & 2 & 1 \\
\hline Centro & 3 & 3 & 2 & 2 & 2 & 2 & 3 \\
\hline Tabela 01: Impactos & Amben & & & & \\
\hline
\end{tabular}

Tabela 01: Impactos Ambientais no entorno do Ribeirão Taboão

A cada tipo de impacto, é atribuído um valor entre 0 e 3 , variando do impacto nulo (0), para o impacto marcante (3):

(0) $=$ impacto nulo

(1) = impacto mínimo

(2) = impacto visível

(3) = impacto marcante

Obs: Esta matriz tem como base:

- PROPOSTA DE UMA MATRIZ PARA AVALIAÇÃO DE IMPACTOS AMBIENTAIS, de Suetônio Mota e Marisete Dantas de Aquino.

\section{Conclusões:}

O presente trabalho demonstra que, com o auxilio da Cartografia Ambiental é possível representar de maneira fidedigna os impactos ambientais de áreas como a do entorno de um Ribeirão do centro de uma cidade. Com o auxílio da visita de campo, se comprovou a existência de diversos impactos, que posteriormente foram transferidos para o Software SPRING, para a confecção de Mapas Temáticos mais lúdicos, através da importação de símbolos evocativos referentes a tais impactos. 


\section{Referências:}

FERNANDES, B.J; ROCHA, G.C. Preparação de mapas de percepção de riscos ambientais: uma proposta metodológica para a educação nas escolas. Anais do $6^{\circ}$ Simpósio Brasileiro de Cartografia Geotécnica e Geoambiental, Uberlândia. 2007.

JOLY, F. A Cartografia. Campinas, Papirus, 1990.

Le Sann, J.G. O papel da Cartografia Temática nas pesquisas ambientais. 2005. Disponível em <http://www.geografia.fflch.usp.br/publicacoes/RDG/RDG_16/Janine_Le_Sann.pdf> Acesso em: dez. 2008.

MARTINELLI, Marcello. Cartografia Ambiental: uma cartografia diferente? São Paulo: Revista do Departamento de geografia v. 7, p. 61-80, 1994. Disponível em: <http://cartografiaambiental.blogspot.com/>. Acesso em: abr. 2008.

MARTINELLI, M; PEDROTTI, F. A Cartografia nas unidades de paisagem: questões metodológicas. 2001. Disponível em: <http://www.geografia.fflch.usp.br/publicacoes/RDG/RDG_14/RDG14_Martinelli.pdf>.Acesso em: mai. 2008.

MOTA, S; AQUINO, M. D. de. Proposta de uma Matriz para avaliação de Impactos Ambientais. 2002. Disponível em:<http://www.bvsde.paho.org/bvsacd/sibesa6/ccxiii.pdf> Acesso em: jul. 2009.

OLIVEIRA, I. J. de. A linguagem dos mapas: utilizando a Cartografia para comunicar. 2004. Disponível em: <www.observatoriogeogoias.com.br/observatoriogeogoias/artigos_pdf/OLIVEIRA,\%20Ivanilton\%20Jose.pdf> Acesso em: mai. 2008. 